Armando Arredondo'

Carlos Carrillo"

Alexis Zuñiga"

\section{Economic burden of expected epidemiological changes in diseases related to tobacco, Mexico}

\section{Impacto econômico das mudanças epidemiológicas esperadas nas doenças associadas ao tabaco, México}

Health Services Unit. Research Center on Health Systems. Cuernavaca, Mexico

II Instituto Nacional de Salud Pública. Cuernavaca, Mexico

\section{Correspondence:}

Armando Arredondo

National Institute of Public Health

Av. Universidad 655

Col. Sta. Maria Ahuacatitlán

CP 62508

62508 Cuernavaca, Morelos, Mexico

E-mail: aarredon@insp.mx

\section{ABSTRACT}

OBJECTIVE: To determine health care costs and economic burden of epidemiological changes in diseases related to tobacco consumption.

METHODS: A time-series analysis in Mexico (1994-2005) was carried out on seven health interventions: chronic obstructive pulmonary diseases, lung cancer with and without surgical intervention, asthma in smokers and nonsmokers, full treatment course with nicotine gum, and full treatment course with nicotine patch. According with Box-Jenkins methodology, probabilistic models were developed to forecast the expected changes in the epidemiologic profile and the expected changes in health care services required for selected interventions. Health care costs were estimated following the instrumentation methods and validated with consensus technique.

RESULTS: A comparison of the economic impact in 2006 vs. 2008 showed $20-90 \%$ increase in expected cases depending on the disease $(\mathrm{p}<0.05)$, and $25-93 \%$ increase in financial requirements $(p<0.01)$. The study data suggest that changes in the demand for health services for patients with respiratory diseases related to tobacco consumption will continue showing an increasing trend.

CONCLUSIONS: In economic terms, the growing number of cases expected during the study period indicates a process of internal competition and adds an element of intrinsic competition in the management of preventive and curative interventions. The study results support the assumption that if preventive programs remain unchanged, the increasing demands for curative health care may cause great financial and management challenges to the health care system of middle-income countries like Mexico.

KEY WORDS: Smoking, epidemiology. Smoking, trends. Health care costs. Health expenditures. Time series studies. Mexico. Models, statistical. 


\section{RESUMO}

OBJETIVO: Avaliar os custos da atenção médica a doenças associadas ao tabagismo e o impacto econômico das mudanças epidemiológicas.

MÉTODOS: Análise de série temporal no México (1994-2005) de sete intervenções médicas em relação a: doença pulmonar obstrutiva crônica, câncer de pulmão com e sem intervenção cirúrgica, asma bronquial em fumantes e não-fumantes, tratamento com adesivos para deixar de fumar, tratamento com goma de mascar. As mudanças epidemiológicas esperadas e as necessidades financeiras para atender a demanda de serviços foram avaliadas pelos modelos probabilísticos de Box-Jenkins. Os custos foram determinados de acordo com método de instrumentação e a técnica de consenso.

RESULTADOS: A comparação do impacto das mudanças epidemiológicas previstas para 2006 e 2008 mostrou incremento de $20 \%$ a $90 \%$, dependendo do tipo de intervenção. O incremento nos custos da atenção médica foi de $25 \%$ a $93 \%$. Há indícios que a demanda de serviços de saúde para as intervenções investigadas continuarão aumentando.

CONCLUSÕES: Em termos econômicos, o aumento na quantidade de casos esperados refletem um fenômeno de competição interna em relação ao uso dos recursos adicionais entre atividades de promoção e prevenção da saúde relacionada ao tabagismo. Se não houver mudanças nos programas de prevenção, haverão desafios econômicos de alto impacto no financiamento dos sistemas de saúde.

DESCRITORES: Tabagismo, epidemiologia. Tabagismo, tendências. Custos de cuidados de saúde. Gastos em saúde. Estudos de séries temporais. México. Modelos estatísticos.

\section{INTRODUCTION}

Major advances in medicine and technology have been associated with escalating expenditure on health since the 1960s. All countries are facing fiscal constraints in health care. As the limits of medicine and how political and economic forces shape health care are increasingly recognized, it becomes necessary to question personal and social meanings of illness and what it means to seek help from health systems, communities and from those empowered to provide health care. ${ }^{1,2}$

In this context, interest in the costs of cigarette smoking for health care derives from the need to identify the economic burden that smoking imposes on a society in the perspective of epidemiological transition. ${ }^{4,8}$ According to the World Health Organization, worldwide mortality from tobacco is likely to rise from about four million deaths a year in 1998 to about 10 million a year in 2030 . In other words, tobacco will cause about 150 million deaths in the first quarter of the century and 300 million in the second quarter. The same report concludes that half of these deaths will occur in the 35-69 years age group, including many in productive middle age, with an average loss of 20-25 years of life. ${ }^{7,18}$
Smoking is the main preventable risk factor particularly for non-communicable diseases, namely lung cancer and a number of cardiovascular and respiratory diseases. The smoking epidemic varies among countries. In developed countries, cardiovascular disease is the most common smoking-related cause of death. Tobacco-related cancer comprises $16 \%$ of the total annual incidence of cancer cases in developed countries, while the corresponding rate in developing countries is $10 \% ., 5$ In China, smoking causes far more deaths from chronic respiratory diseases than from cardiovascular disease. ${ }^{3}$ In Mexico, according to official data, approximately 40,000 persons per year die from smoking-related respiratory diseases, and approximately 100,000 patients demand health care services to treat these illnesses. ${ }^{14}$

The economic impact of the smoking epidemic and their implications on the recent changes in resource allocation methods and practices in health care raise several dilemmas for policy and decision makers, particularly in the context of health care reform. ${ }^{6 * *}$ First, the double burden of communicable and non-communicable diseases in transition countries: and the ever wider variety

* Health System Research. National Institute of Public Health. Project: costs and financing consequences from changes in epidemiological profile. 1995-2005. Final technical report. Cuernavaca, México: 2006: 23-48. 
of possible medical interventions increase health care costs and impose an ever greater burden on national and state budgets, thus hindering the effectiveness of cost-containment efforts. ${ }^{13}$ Second, the demand for health care, and the equity for resource allocation are greater and more diverse than ever before, especially in middle-income countries. ${ }^{12, *}$

Further, the burden of smoking-related illness is expected to increase the demand for costly treatment alternatives, which will compete with other demands for scarce resources. Therefore, there is a need to estimate the true costs of smoking-related illness in order to evaluate the economic impact on the health care system. ${ }^{15}$ In this sense, the objective of the present study was to assess health care costs and economic burden of epidemiological changes in tobacco-related diseases focusing on respiratory diseases.

\section{METHODS}

A time-series analysis was carried out in Mexico. There were assessed annual health care costs of chronic obstructive pulmonary disease (COPD); lung cancer; asthma in non-smokers and smokers per case (or per year); and full treatment course with nicotine gum and nicotine patch. Secondly, it was also sought to describe the financial consequences of changes in the epidemiological profile of these diseases and treatments.

Specialists were interviewed to determine the case management, which are all the diagnostic and therapeutic actions taken for the condition under study. In regard to COPD, lung cancer, non-smokers and smokers with asthma, definitions relied on case management practices in secondary and tertiary health care. For the full treatment course with nicotine gum and nicotine patch, primary health care was considered as the appropriate level. The definition of case management for each disease took into consideration the natural history of the disease, demand for health care, results from the review of clinical records, and clinical (epidemiologists) and administrative expert consensus.

In order to identify data on unitary costs of health inputs, interviews were conducted with experts in case management of each intervention: seven medical doctors, seven managers/economists, and seven epidemiologists. The information these experts reported was complemented with data on procurement.

The case management included all inputs and production functions required to meet all care requirements for each intervention or disease. In order to determine procedures and inputs in case management for cost containment, the methodology for classifying hospital patients and case management was followed, as well as the instrumentation technique. ${ }^{11, *}$

Nine data collection forms were designed to record the different processes, procedures and resources (production and input functions). They included different categories of analysis such as: infrastructure; human resources in physician hours, nurses' hours and administrative personnel hours; laboratory studies; complementary studies; average number of bed days; components of the medicinal curative therapy; components of intensive therapy; contracted services; general services; and other resources, processes, procedures and observations.

Once the production functions (medical consultations, drugs, emergency room care, hospitalization, laboratory studies, and others) required to the average case management were determined, this information was then compared to that collected from clinical records of the diseases to complement and/or validate the information provided by the experts. The clinical records were obtained from databases of Mexican Ministry of Health national reference hospitals; for each intervention, a sample was studied with $10 \%$ of cases in an annual period.

To determine health costs three databases of health care costs in the public sector of Mexico were used.* These databases are representative of national reference hospitals and of relative costs of chronic respiratory diseases. The costs of the following production functions were identified based on the review of costs of a bed day; intermediate therapy; emergencies and intensive care; laboratory studies; hours of operating room usage; and inputs involved in events to be priced. After having obtained unit costs for each process or procedure, numerical estimates were made using a calculation sheet. Depending on the amount of each measurement unit used per patient case, it was possible to obtain the total cost of each resource, process or procedure, and similarly, to calculate the total average cost of the case management.

To forecast future financial consequences and economic impact, the estimation of the demand for health care was made on the basis of the demand experience at a national public referral hospital for respiratory diseases. Official statistics were used for information, and a database was constructed to gather monthly morbidity and utilization trends from 1994 to 2005 . Four probabilistic models were developed to determine expected cases from 2006 to 2008, using mainly Box-Jenkins time-series analysis and the Stat Graphics statistical software program. ${ }^{9}$ Variables analyzed included changes of morbidity rates for the period and changes

* Health System Research. National Institute of Public Health. Project: costs and financing consequences from changes in epidemiological profile. 1995-2005. Final technical report. Cuernavaca, México: 2006: 23-48. 
in health policies and programs for the four diseases. The following steps were taken in the development of the probabilistic models:

1. Using observed cases from recent years, probabilistic models were identified and developed. Determining variables for each disease were also identified. Then the quality of the information was revised and the self-correlation coefficient among the observed cases was calculated in order to determine the validity of the data. The last ten years were considered the valid period for the analysis.

2. Once the model was identified, the number of expected cases for each disease for the 2006-2008 period was estimated. The trends of expected results were compared to results observed during the last ten years so that a similar behavior would be guaranteed in the disease's risk factors as well as in health programs to respiratory diseases.

3. To determine a better adjustment of each model and of estimated cases, it was applied the Box-Pierce Chi-square. Finally, the most adequate model was defined, dividing the economic analysis 1 . i n t o direct and indirect costs.

The number of cases was projected for a three-year period, using a $95 \%$ confidence interval. According to evidence in other studies, ${ }^{15,16, * *}$ expert consensus and data from the National Survey of Chronic Disease* were used to identify the proportion of selected diseases attributable to smoking.

Once case management costs and the number of expected cases for each projected year were estimated, data processing was carried out using a spreadsheet to compute the case management cost for each selected disease. The financial consequences of expected epidemiologic changes were then determined by means of an econometric adjustment factor to control for future inflation rates.

\section{RESULTS}

Regarding the definition of case management for each intervention, results were as follows:

COPD was defined as annual outpatient case management without complications (without information suggestive of respiratory failure or infections). First medical visit, diagnostic tests (X-rays, electrocardiography, pulmonary function test, arterial gasometry, white blood cell count, blood chemistry, throat secretion swabbing). Outpatient drug treatment (bronchodilators, glucocorticoids and mucolytic for 10 days). Three sessions of postural drainage for secretions. Annual follow-up: six medical visits at the primary care level; two medical visits at the secondary care level, including one X-ray, five gasometries, four white blood cell counts and five pulmonary function tests.

For lung cancer, the annual average case management without complications was outpatient case management without complications. An initial medical visit, 12 follow-up visits with secondary care specialist and six referrals to tertiary care specialist. Diagnostic exams: one sputum cytology, one bronchoscopic biopsy and two X-rays. Surgical intervention, ten hospital days (pre- and post-surgery) and 15 radiotherapy sessions. Follow-up: outpatient drug treatment with cyclophosphamide doxyrubicine and CCNU (lomustine). Tests: $12 \mathrm{X}$-rays and two sputum cytology.

Annual average case management of bronchial asthma for non-smokers was defined as two acute crises per year: an initial medical visit in a secondary care facility, four secondary care referrals, three annual follow-up medical consultations, two days of emergency room care. Outpatient drug treatment: corticosteroids, antihistaminics. Follow-up: three laboratory studies, one $\mathrm{X}$-ray, and maintenance treatment.

Case management for bronchial asthma for smokers followed the same annual case management as for bronchial asthma for non-smokers, except for: four hospital stays, one medical consultation at tertiary care level, two X-rays, and three more laboratory studies.

For low birth weight babies, annual average case management without complications was defined as an initial medical visit, 18 follow-up visits with secondary care specialist. Medical diagnostic exams: white blood cell count, blood chemistry, serum electrolytes (calcium and iron), stool culture, blood proteins (two), and urinalysis (two). Therapy: food supplements for one year.

Annual average case management of full treatment course with nicotine gum without complications was defined as: outpatient case management without complications at primary care level. An initial medical visit; 11 follow-up visits; ten group meetings of special therapy during the first month of treatment and three gums per day for two months.

For full treatment course with nicotine patch, the annual average case management without complications was defined as: outpatient case management without complications at primary care level. An initial medical visit; 11 follow-up visits; ten group meetings of special therapy during the first month of treatment and one patch per day for one month.

* Secretaria de Salud, Encuesta Nacional de Enfermedades Crónicas. Sistema Nacional de Salud. Factores de riesgo en daños a la salud. México DF. 2003. 
Table 1. Average costs (in US\$) of case management in the public health sector. Mexico, 1994-2005.

\begin{tabular}{lc}
\hline Disease/intervention & $\begin{array}{c}\text { Cost of case } \\
\text { management }\end{array}$ \\
\hline Chronic obstructive pulmonary disease & 370.00 \\
$\begin{array}{l}\text { Lung cancer per year } \\
\text { (without surgical intervention) }\end{array}$ & 730.00 \\
$\begin{array}{l}\text { Lung cancer per year } \\
\text { (with surgical intervention) }\end{array}$ & $1,920.00$ \\
Non-smokers with asthma per year & 811.00 \\
$\begin{array}{l}\text { Smokers with asthma per year } \\
\text { The cost of full treatment course with } \\
\text { nicotine gum }\end{array}$ & 987.00 \\
$\begin{array}{l}\text { The cost of full treatment course with } \\
\text { nicotine patch }\end{array}$ & 224.00 \\
\hline
\end{tabular}

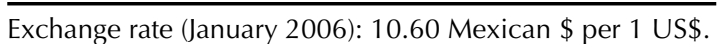

The average cost of treatment per patient was determined according to the definition of case management identified by experts and validated with data from clinical files. Only in the case of lung cancer was necessary to differentiate between the cost of case management with or without surgical intervention. This was because approximately $50 \%$ of patients with lung cancer in Mexico require surgical intervention in addition to drug therapy and radiotherapy. Case management direct economic costs were measured using as a reference the costs of inputs and salaries as of January 2006. Average costs for each disease or intervention are shown in Table 1.

The results of the proportion of disease attributable to smoking were: $80 \%$ in total cases of COPD, $25 \%$ in total cases of cardiovascular diseases, and $85 \%$ in total cases of lung cancer (Table 2). Data on asthma refer to the expected asthma cases associated with tobacco consumption, as described in the Methods section.

The four selected diseases showed significant increase in financial resources required to provide health care services, particularly in the case of COPD and lung cancer, since inflation rates add up to the increase in the number of expected cases (Table 3 ).

\section{DISCUSSION}

Although conducted only in Mexico, the findings of the present study related to trends in costs, epidemiological changes, health systems, and financial consequences of respiratory diseases related to tobacco consumption are similar in most Latin American countries. ${ }^{17,19}$ Therefore, global and qualitative findings can be used to address the health policy, planning and financing process in view of the economic impact of these diseases in any Latin American country and particularly in middleincome countries of the region.

In fact, part of the usefulness of the results for these countries is that general tendencies of economic and epidemiological findings may be taken as references, but not the specific data. Therefore, the number of expected cases and the cost of case management are only applicable to Mexico, but the tendencies in incremental rates, in epidemiological terms as well as in terms of economic impact, would be similar in middle-income Latin American countries.

The results of the case management costs of the present study are applicable only to the public health care system run by the government, which is currently the

Table 2. Number of cases expected per year, according to disease in a national public referral hospital. Mexico, $2006-2008$.

\begin{tabular}{lcccc}
\hline Disease & 2006 & 2007 & 2008 & p-value \\
& & $\mathrm{N}(95 \% \mathrm{Cl})$ & \\
\hline Chronic obstructive pulmonary disease & $235(218-252)$ & $267(248-286)$ & $304(284-324)$ & $<0.05$ \\
Asthma & $1,840(1,792-1,888)$ & $1,906(1,854-1,958)$ & $2,165(2,110-2,220)$ & $<0.01$ \\
Lung cancer & $883(848-918)$ & $967(927-1,007)$ & $1,013(968-1,058)$ & $<0.05$ \\
Full treatment course with nicotine gum & $520(513-527)$ & $708(699-717)$ & $995(984-1,006)$ & $<0.001$ \\
\hline
\end{tabular}

Table 3. Cost (in US\$) expected per year for management of a disease in a national referral public hospital. Mexico, 20062008.

\begin{tabular}{lrrr}
\hline Disease & \multicolumn{1}{c}{2006} & \multicolumn{1}{c}{2007} & \multicolumn{1}{c}{2008} \\
\hline Chronic obstructive pulmonary disease & $69,520.00$ & $79,032.00$ & $89,984.00$ \\
Asthma & $454,020.00$ & $470,305.00$ & $509,538.00$ \\
Lung cancer & $1,441,056.00$ & $1,578,144.00$ & $1,653,216.00$ \\
Full treatment course with nicotine gum & $100,360.00$ & $136,644.00$ & $192,035.00$ \\
\hline
\end{tabular}

Exchange rate (January 2006): 10.60 Mexican \$ per 1 US\$. 
main source of health care in Mexico. Costs in the private health care sector would be higher because of higher costs of provider input. The economic evaluation method used in the present study implicitly included as a variable the quality of care provided by these services. This is relevant because in terms of economic evaluation, results and their utilization are in doubt when a minimal quality of care is not controlled.

With regard to the economic impact and financial consequences of tobacco consumption on the health care system, the cost results of this study indicate that it is important to limit the relative risk of smoking for the interventions to be studied. Then it will be valid to quantify the economic weight of health risks caused by smoking. Other interventions are associated with other risk factors, where smoking is just one element that leads to the demand for care, and in several cases, it is not the most important.

On the other hand, there is an internal competition for resources generated by changes in the epidemiologic profile. It is noteworthy the hypothesis that costs and financial consequences of changes in the epidemiologic profile has two elements to be considered for future health policies. These are particularly preventive and curative health care programs for each selected disease, even if health resource allocation increases.

Results support the conclusion that if health care programs and risk factors for each selected disease remain unchanged for the next three years, the demand for health services will show an upward trend in all cases. Inaction by the government in health prevention and promotion regarding this study's findings will have financial consequences for resource allocation decision making. A greater impact can be expected at the time of financial resource allocation to meet the demands for medical care, considering the internal competition for service production inputs.

The information presented, particularly the estimation of the amounts and costs of critical inputs and expected cases of disease, is an indispensable tool for decision making in health policy strategic planning directed at covering the expected increase in demand caused by the study diseases in the coming years. In terms of health policy, the results of the present study may be used at three levels: health economic research, training of human resources, and producing and financing of health care services to meet the demand for health services related to tobacco consumption.

Expected changes in the epidemiologic profile will produce a demand for financial resources which will overwhelm allocated resources, especially if health care expenditure trends in past years are considered. Another important consequence is that the internal competition for financial resources was seen. For example, the fi- nancial resources required to meet the demand for lung cancer compete with resources required for nicotine gum treatment to stop smoking. This situation is more complicated because the cost of services for $20 \%$ of expected lung cancer cases is equivalent to what it would cost to meet $100 \%$ of the demand for nicotine gum treatment to stop smoking. A similar situation is observed when analyzing the financial amounts within each selected disease, comparing hospital versus outpatient case management costs.

As for the results validity, it is problematic to undertake a comparative analysis of validity across countries. For example, when comparing the results of health care costs for lung cancer in middle-income countries, the results in the present study were similar to those reported by a World Bank study developed in $1993^{10}$ (US\$ $1,367.00$ per case management in adult patients aged 55-60 years). However, the methodology used to determine the costs of case management was different, as it considered the case management applicable to all adult patients, not only those 55-60 years of age. Thus, the importance of specifying the method of analysis used and the inputs and production functions that were included in the average cost calculation for comparability.

The present findings could be included in cost-benefit and cost-effectiveness analyses of intervention alternatives for each selected disease in health research policies. The results could help policymakers in identifying mechanisms and amounts to invest in prevention, curative or rehabilitation activities. On the other hand, considering that this was an evaluative forecasting study, it would be advisable to monitor the costs of health services and carry out an annual analysis of the costs of epidemiologic profile changes in order to compare the projected findings with real life situations. Such a comparison would provide greater methodological support to extend the application of cost-monitoring systems to other diseases, or to overturn the structure and design of the methods. In long-term projection, data used in probabilistic models should be periodically updated (every two years) so that projections are also updated four years ahead of the year of update. It is recommended that the period not extend beyond five years since the confidence intervals would then be questionable.

In conclusion, the present study provided basis for identifying the financial consequences of health priorities in demands related to tobacco consumption in the short, medium and long term. Similar approaches could be used as a decision making tool in matters of health services production for specific demands, but above all in matters of health services financing. Financial allocation mechanisms may be designed based on these studies. Tax policy instruments may also be justified and 
negotiated in order to direct more financial resources towards health services based on an increase in taxes on cigarettes. This increase would necessarily have to be directly proportional to the financial consequences on the health system due to the demand for services related to tobacco consumption.

\section{REFERENCES}

1. Arredondo A, Zuñiga A. Epidemiological and economic burden of hypertension in Latin America: evidence from Mexico. Am J Hypertens. 2006;19(6):140-7.

2. Arredondo A. Gerencia y economía de servicios de salud. México: Centro Interamericano de Estúdios em Seguridad Social; 2005. Conceptos básicos para el análisis del mercado de servicios de salud; p. 163-74.

3. Bartecchi CE, Mackenzie TD, Schrier RW. The global tobacco epidemic. Sci Am. 2005; 272(5):44-51.

4. Bartecchi CE, Mackenzie TD, Schrier RW. The human costs of tobacco use (2). N Engl / Med. 1994;330(13):975-80.

5. Benatar SR. Respiratory health in a globalizing world. Am J Respir Crit Care Med. 2001;163(5):1064-7.

6. The catastrophic failures of public health. Lancet. 2004;363(9411):745.

7. Practice expense costs in pulmonary and critical care practices. Is providing patient care still economically feasible? Am J Respir Crit Care Med. 2001;163(7):1524-7.

8. Miller VP, Ernst C, Collin F. Smoking-attributable medical care costs in the USA. Soc Sci Med. 1999;48(3):375-91.

9. Murray A. Statistical modelling in GLIM. New York: Oxford University Press; 2003. Statistical modelling and statistical inference: measurement error in the explanatoriy variables: Box-Jenkins technique; p. 67112.

10. Jamison D, Mosley H, Measham A, Bobadilla JL, editors. Disease control priorities in developing

\section{ACKNOWLEDGMENTS}

To Dr. María de la Luz Kageyama (Instituto Nacional de Salud Publica), and Dr. Raquel Abrantes (Centro Interamericano de Estudios en Seguridad Social) for their technical advice on the management of statistical tests.

countries. Washington: Oxford University Press; 1994. Cost-effectiveness of treatment: lung cancer; Chap 21, p. 540-5.

11. Noronha MF, Veras CT, Leite IC, Martins MS, Braga Neto F, Silver L. The development of diagnosis-related groups-DRGs. Methodology for classifying hospital patients. Rev Saude Publica. 1991;25(3):198-208.

12. Public Health Service. Report of the Advisory Committee to the Surgeon General of the Public Health Service. Smoking and health. Washington: U. S. Department of Health, Education, and Welfare; 1964. p. 387. (PHS Publication, 1103)

13. Rice D, Hodgson TA, Sinsheimer P, Browner W, Kopstein AN. The economic costs of the health effects of smoking, 1984. Milbank Q. 1986;64(4):489-547.

14. Sansores R. Evaluación del programa para dejar de fumar del INER. Rev Inst Nac Enf Resp. 1998;11(1):2935.

15. Samet JM. Los riesgos del tabaquismo activo y pasivo. Salud Pública Méx. 2002;44 Suppl 1:S144-60.

16. Warner KE. The economics of tobacco: myths and realities. Tob Control. 2000;9(1):78-89.

17. World Bank. World Development report 1993: investing in health. Washington; 1993.

18. World Health Organization. The world health report 1999: making a difference. Geneva; 1999. Combating the tobacco epidemia; p. 65-79.

19. Panamerican Health Organization. Health situation in the Americas: basic indicators 2004. Washington, DC; 2005. p. 234-56. 